\title{
Pain Prevalence, Characteristics, and Impact Among People with Hemophilia: Findings from the First Portuguese Survey and Implications for Pain Management
}

\author{
Patrícia Ribeiro Pinto, PhD, ${ }^{*}+$ Ana Cristina Paredes, MSc, ${ }^{*}+$ and Armando Almeida, PhD, ${ }^{*}, \dagger$ \\ * Life and Health Sciences Research Institute (ICVS), School of Medicine, University of Minho, Braga, Portugal; ${ }^{\dagger}$ ICVS/3B's - PT Government Associate \\ Laboratory, Braga/Guimarães, Portugal
}

Correspondence to: Patrícia R. Pinto, PhD, Life and Health Sciences Research Institute (ICVS), School of Medicine, Campus de Gualtar, University of Minho, 4710-057 Braga, Portugal. Tel: +351253604926; Fax: +351253604809; E-mail: patipinto@med.uminho.pt.

Funding sources: This work was supported by the Novo Nordisk HERO Research Grant 2015. PRP is the recipient of a postdoctoral grant (SFRH/BPD/ 103529/2014) from the Portuguese Foundation of Science and Technology.

Conflicts of interest: Nothing to declare.

\begin{abstract}
Background. Hemophilia is a rare disorder characterized by spontaneous bleeding, with pain being a critical aspect. However, a systematic assessment of hemophilia-related pain in Portugal has never been conducted. Objective. To understand the pain experience among Portuguese people with hemophilia (PWH) by describing its prevalence, characteristics, and impact and uncovering intervention needs in the realm of hemophilia-related pain care. Methods. A cross-sectional observational survey, with age-adapted versions of questions concerning pain, emotional distress, and quality of life, was answered by 104 adults, 21 children/teenagers (10-17 years), and 19 children (1-9 years). Results. Pain was reported by $82(78.8 \%)$ adults, $16(76.2 \%)$ children/teenagers, and $13(68.4 \%)$ children, with $65(62.5 \%), 13(61.9 \%)$, and eight $(42.1 \%)$ of them reporting pain lasting more than three months, respectively. The mean number of pain locations (SD) was 5.23 (3.95) for adults, 4.13 (3.48) for children/teenagers, and 3.15 (1.99) for children age 1-9 years, with lower limbs pain causing the greatest negative impact. More frequent paintriggering factors were physical effort/movements $(61,74.4 \%)$ for adults and hemarthrosis for younger groups (children/teenagers: 14, 87.5\%; children: 9, 69.2\%). Bleeds yielded the highest mean pain intensity (adults: $M$ [SD] $=5.67$ [2.09]; children/teenagers: $M[S D]=5.69$ [2.15]). Adults with pain revealed more anxiety (odds ratio $[O R]=1.698$, $P=0.003$ ) and depression ( $\mathrm{OR}=1.961, P=0.025$ ) and lower quality of life (OR $=0.928, P=0.001)$. Conclusions. The current findings highlight the high prevalence, duration, and frequency of pain at all ages, its potentially simultaneous acute and chronic nature, its likelihood to affect multiple locations concurrently, and its detrimental impact. Important insights concerning intervention needs are presented, ultimately contributing to the improvement of hemophilia-related pain management and patient care.
\end{abstract}

Key Words: Hemophilia; Hemarthrosis; Chronic arthropathy; Emotional Distress; Health-Related Quality of Life

\section{Introduction}

Hemophilia is an X-chromosomal rare disorder affecting approximately 1 in 10000 births [1]. It is characterized by deficiency or absence of coagulation factors in the blood, either factor VIII (hemophilia A) or IX (hemophilia B), and is associated with a pattern of spontaneous bleeding, mainly into the joints (hemarthrosis), which is the hallmark of the disease [1-3]. The bleeding rate is influenced by the severity of the hemophilia, determined according to coagulation factor level concentration (mild: $5-40 \%$ of normal factor level; moderate: $1-5 \%$ of normal; severe: $<1 \%$ of normal) [4]. The mainstay of treatment for hemophilia is factor replacement therapy, either on demand or prophylactically. Prophylaxis is currently recommended for people with severe hemophilia from an early age, but it was not accessible to patients 
who are now in their adult years, who therefore grew up without some form of preventive treatment. In addition, the high cost of this treatment remains a significant obstacle to generalized access, thereby preventing some adult patients from fully benefiting from prophylaxis [2], whereas children have broader access to it. A recent survey showed that access to prophylaxis by Portuguese adults $(26-50 \%)$ is still below other countries, such as Belgium, Ireland, and the Netherlands, wherein 76$100 \%$ of adults have access to prophylaxis [5]. For children and teenagers in Portugal, access to prophylaxis is higher when compared with adults, covering $76-100 \%$ of patients. This matches the practices of developed countries like Belgium, Finland, Ireland, and Norway [5].

The potential development of inhibitors to factor replacement, which neutralize the effectiveness of clotting factor concentrates, also needs to be considered as an important complication of treatment [1]. Hemarthrosis is a very painful event, accompanied by swelling, stiffness, and restricted mobility [3,6,7]. Repeated joint bleeds cause the accumulation of intra-articular blood, triggering a series of interdependent biological processes that lead to synovial inflammation. This progressively contributes to irreversible joint degeneration and development of chronic hemophilic arthropathy, characterized by joint deformity, functional limitations, disability, and chronic pain, ultimately requiring surgical intervention [8-10].

Although few studies have addressed the pain characteristics, impact, and management of patients with hemophilia, it is possible to learn from surveys of other countries about its pervasiveness. In one study, $81 \%$ of adults with severe hemophilia reported pain, occurring daily in two-thirds of them [11]. Likewise, a survey performed across several countries revealed that $89 \%$ of adult people with hemophilia (PWH) experienced pain interfering with daily activities [12]. Specifically concerning children and adolescents, there is limited survey information on this subject $[13,14]$.

Recent figures from the United States [15] found a chronic pain prevalence of $66 \%$ among PWH, with $20 \%$ complaining of acute pain and $32 \%$ experiencing concurrent acute and chronic pain. Interestingly, and beyond the acknowledged relationship between chronic pain and worst psychological functioning and low quality of life [12], the study by Witkop et al. [15] further highlighted that those complaining of both acute and chronic pain were more likely to be depressed and exhibit lower quality of life. Concerning pain in general and psychosocial factors, chronic pain is known to be strongly associated with worst physical and mental health-related quality of life among PWH [16]. Along these lines, it has been suggested that psychological health fully mediates the effect of pain on subsequent functional limitations or disability [17].

Pain is therefore a common and debilitating symptom, whether acute (hemarthrosis) or chronic (hemophilic arthropathy), or even occurring concomitantly within the same individual. This latter feature constitutes an uncommon symptomatic presentation, rendering an additional burden to patients and posing a particular challenge to health care professionals.

Surprisingly, no hemophilia-related pain data have been comprehensively assessed and reported in Portugal, wherein there is an estimated prevalence of approximately 700 cases of hemophilia [18].

Recently, strong calls to action have been made on the need to improve pain assessment and management in the hemophilia field $[19,20]$, as a comprehensive and thorough assessment of pain is the basis for optimal management and treatment. In addition, given the growing emphasis on patient-centered care, the understanding of patients' perspectives is mandatory to identify the most cost-effective hemophilia treatment approaches [21].

Hence, a better understanding of how Portuguese PWH describe pain and cope with it, as well as knowledge of their own perception about pain impact, treatments, and difficulties, is critical to improving the clinical management of hemophilia among Portuguese patients, informing tailored pain management strategies and policy decision-making.

This study aims to understand, for the first time, the pain experience among PWH in Portugal, describing its prevalence, characteristics, and impact and uncovering intervention needs in the realm of hemophilia-related pain care. Given the lack of official information on pain among Portuguese $\mathrm{PWH}$, this study will contribute to improving knowledge about hemophilia patients living in Portugal, thereby pointing to potential critical/problematic areas that can be improved in the Portuguese context.

\section{Methods}

\section{Study Design}

This was a national, cross-sectional, large observational study performed in the scope of the first Haemophilia National Survey conducted in Portugal, among PWH registered with the Portuguese Haemophilia Association (APH).

An envelope containing an invitation to participate and the description of study objectives, in addition to the informed consent and the questionnaires, was sent by mail to all males registered in APH as having hemophilia, a total of 500 individuals. The surveys were sent in October 2016 and received by May 2017. A telephone call was made to all PWH who had not sent the survey after three months (January 2017), both as a reminder and as a means to clarify possible doubts. Approval for this study was obtained from the Ethical Committee at the University of Minho and the Portuguese Data Protection Agency, and the study is registered at clinicaltrials.gov (NCT02870114). Informed consent was obtained from the participants or legal guardians. 


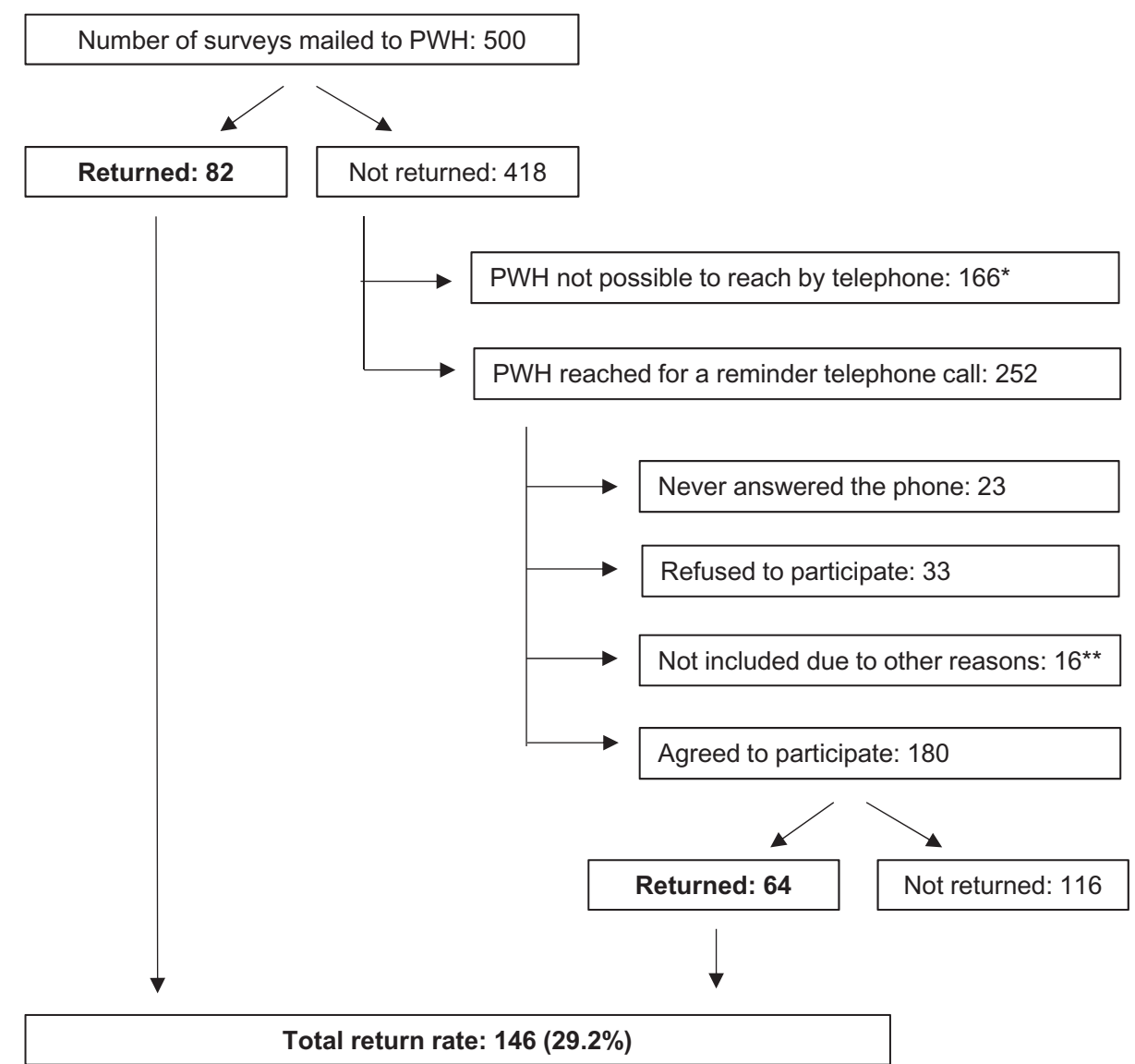

\begin{abstract}
${ }^{*}$ Reasons for impossibility to reach by phone are: number not listed $(n=84)$ and telephone number wrong or disconnected $(n=82)$.

** Other reasons for non participation are: living abroad $(n=6)$, decease $(n=2)$, unable to answer due to other comorbidities (blindness, cerebral palsy and cognitive impairment) $(n=3)$, bad phone reception $(n=3)$ and increased factor activity level $(>40 \%)$ due to liver transplant $(n=2)$.
\end{abstract}

Figure 1. Flowchart of study participants and reasons for nonparticipation.

\section{Participants}

Participants included in this survey were male PWH with hemophilia A or B of all ages. Exclusion criteria were inability to read and write or to consent to voluntary participation.

To comprehensively assess PWH of all ages, similar but age-appropriate versions were developed, varying according to target age (adults vs teenagers and children) and mode of response (self-report vs proxy): 1 ) adults (self-report): age $\geq 18$ years; 2 ) children/teenagers (self-report): age $10-17$ years; 3 ) parents (proxy version): age $0-9$ years. From the $146 \mathrm{PWH}$ who returned the survey $(29.2 \%$ return rate), two were excluded due to missing data on pain measures, leaving 144 participants in the final sample. Figure 1 shows the flow of participants in the survey, including reasons associated with nonparticipation.

\section{Measures}

For the purposes of the current study, wherein the focus is the study of the pain prevalence, characteristics, and impact among Portuguese PWH, the analyses exclusively considered pain-related data in all age ranges. Additionally, and apart from demographic and clinical data, further analyses including anxiety, depression, and health-related quality of life in adults were performed. A description of all these measures is below:

1. Sociodemographic Questionnaire: Gathers patients' data concerning age, education, marital status, professional status, etc.

2. Clinical Questionnaire: Collects general clinical information regarding, for instance, hemophilia type and severity, type and regimen of hemophilia treatment, joint bleeding episodes, and comorbidities.

3. Multidimensional Haemophilia Pain Questionnaire (MHPQ; developed by the research team): Includes four initial items aimed at an accurate distinction between acute and chronic pain, followed by nine dimensions concerning hemophilia-related pain experienced in the previous year. If no pain is reported during a one-year time frame, the remaining questions are not answered. These questions are divided in nine dimensions, which are described bellow:

- Pain locations: Questions about all hemophilia-related pain locations, leading to the establishment of a "number of pain 
locations" measure. In addition, participants are asked to choose the "most painful location" and the "pain location that caused the greatest impact."

- The remaining questions should be answered based on the pain that yields the greatest impact.

- Duration: Queries how long ago the pain with greatest impact started.

- Frequency (and temporal pattern): Asks about how often (e.g., daily, weekly, only during bleeds) the pain occurs, along with description of the time of day when pain is most often experienced.

- Pain-triggering factors: Requires the choice, from a list, of perceived triggers related to pain onset, such as bleeds, climbing stairs, effort, or weather changes.

- Intensity: Assessed specifically in relation to six distinct conditions (bleeding episodes; during physical efforts and/or movement; using stairs; after resting or rising from sitting/lying down; during rest, sitting, or lying down; and accidental or "wrong" movements) that are associated with each triggering factor mentioned above. Intensity is rated on a $0-10$ numerical rating scale (NRS; $0=$ no pain, $10=$ worst imaginable pain). This dimension only figures on the self-report versions, showing good Cronbach's alpha coefficients both for adults $(\alpha=0.88)$ and children/teenagers $(\alpha=0.70)$.

- Interference (etrieved from the Brief Pain Inventory [BPI]) [22]: Evaluates interference of hemophilia-related pain in seven domains: general activity, mood, walking ability, normal work, relations with others, sleep, and enjoyment of life. Although in self-report versions the items are measured according to a $0-10$ NRS $(0=$ no interference, $10=$ completely interferes), in proxy versions the questions are answered according to a five-point qualitative scale ranging from "no interference" to "total interference," with the additional "does not apply" option, in case the item is not applicable to the child (e.g., walking/crawling ability). Reliability scores for interference items are high for both the adult version $(\alpha=0.91)$ and the age $10-17$ version $(\alpha=0.89)$ and adequate $(\alpha=0.79)$ for the proxy version.

- Strategies for pain control: Shows an inventory of several pharmacological and nonpharmacological strategies from which the participants should select the ones they rely on, also pointing the degree of perceived relief on a $0-100 \%$ scale.

- Pain specialists or other therapies: Requires the selection, from a list of 11 specialists or therapies (e.g., hemophilia doctors, anesthesiologists, orthopedists, psychologists, or complementary therapies, such as acupuncture or meditation), of those that participants have consulted or would like to consult to manage pain.

- Satisfaction with treatment: Evaluates global satisfaction with pain treatment through a single question, answered on a fivepoint scale ranging from "very dissatisfied" to "very satisfied."

Finally, each dimension is analyzed separately, and no global pain score is computed for the MHPQ. It can be used with PWH of all ages, but in children from 1-9 years old, it is a proxy version that should be completed by a parent or caregiver, which does not assess pain intensity or degree of relief from pain strategies. To facilitate item understanding, age-appropriate examples are adapted for the items of each version. This questionnaire was originally developed by the research team and has undergone a thorough validation process [23].

- Patient-Reported Outcomes Measurement Information System (PROMIS), anxiety and depression (short forms) [24]: Each form has four items that assess symptoms of anxiety and depression, such as fear (anxiety) or hopelessness (depression). Scores range from 4 to 20, with higher scores indicating more severe symptoms. In the present sample, internal consistency reliability was high both for the anxiety $(\alpha=0.83)$ and depression $(\alpha=0.92)$ subscales.

- A36 Hemofilia-QoL [25]: This is a hemophilia-specific selfreport questionnaire assessing health-related quality of life. The 36 items are divided into nine subscales: physical health $(\alpha=0.89)$, daily activities $(\alpha=0.95)$, joints $(\alpha=0.83)$, pain $(\alpha=0.82)$, treatment satisfaction $(\alpha=0.68)$, treatment difficulties $(\alpha=0.74)$, emotional functioning $(\alpha=0.83)$, mental health $(\alpha=0.82)$, and relationships and social activity $(\alpha=0.92)$. A total score $(\alpha=0.96)$ can also be computed.

\section{Statistical Analysis}

Statistical analysis was performed with IBM SPSS, version 24 (Chicago, IL, USA). The internal consistency of responses to the questionnaires was assessed using Cronbach's alpha [26]. Categorical data are presented as numbers and percentages, and continuous variables are presented as mean $(\mathrm{M})$ and SD and/or median $(\mathrm{Md})$ and range.

Additionally, a set of predictive hierarchical multivariate logistic regression models was conducted to analyze the psychosocial factors (emotional distress and health-related quality of life) associated with the presence of pain among adult PWH. To adjust for the differences between the pain group and the no pain group, potential confounders were included in the model: in this case, age and hemophilia severity (mild, moderate, severe). No such multivariate analysis was computed for the 10-17 and 1-9 age groups due to small sample size.

$P$ values of $<0.05$ were considered statistically significant.

\section{Results}

\section{Prevalence of Pain Among PWH}

The MHPQ was answered by 144 PWH. One-hundred twenty-seven participants $(88.2 \%)$ reported lifetime pain due to hemophilia, and $111(77 \%)$ reported pain in the previous year. Pain lasting over three months occurred in $86(59.7 \%)$ participants, and $46(31.9 \%)$ reported having pain more than once a week. Table 1 shows the prevalence of pain across age groups.

\section{Sociodemographic and Clinical Characteristics of Study Participants (With and Without Pain in the Previous Year)}

Table 2 reveals the sociodemographic and clinical characteristics of the study participants with and without hemophilia-related pain in the previous year. The mean age of adults (SD) was 43.17 (13.00) years for PWH with pain and 45.50 (17.31) years for those without pain. Most adults were married (pain: $46,57.5 \%$; no pain: 15 , 
Table 1. Prevalence of pain due to hemophilia among study participants

\begin{tabular}{|c|c|c|c|c|}
\hline & $\begin{array}{l}\text { Global Sample } \\
(\mathrm{N}=144)\end{array}$ & $\begin{array}{l}\text { Adults Age } \geq 18 \mathrm{y} \\
(\mathrm{N}=104)\end{array}$ & $\begin{array}{l}\text { Children/Teens } \\
\text { Age } 10-17 \text { y }(\mathrm{N}=21)\end{array}$ & $\begin{array}{l}\text { Children (Proxy) } \\
\text { Age } 1-9 \text { y }(\mathrm{N}=19)\end{array}$ \\
\hline Lifetime pain & $127(88.2 \%)$ & $93(89.4 \%)$ & $19(90.5 \%)$ & $15(78.9 \%)$ \\
\hline In the previous year & $111(77 \%)$ & $82(78.8 \%)$ & $16(76.2 \%)$ & $13(68.4 \%)$ \\
\hline Lasting $>3 \mathrm{mo}$ & $86(59.7 \%)$ & $65(62.5 \%)$ & $13(61.9 \%)$ & $8(42.1 \%)$ \\
\hline More than once a week & $46(31.9 \%)$ & $43(41.3 \%)$ & $2(9.5 \%)$ & $1(5.3 \%)$ \\
\hline
\end{tabular}

Table 2. Sociodemographic and clinical information of people with hemophilia with and without pain

\begin{tabular}{|c|c|c|c|c|c|c|}
\hline & \multicolumn{2}{|c|}{ Adults Age $\geq 18$ y $(\mathrm{N}=104)$} & \multicolumn{2}{|c|}{$\begin{array}{l}\text { Children/Teens } \\
\text { Age } 10-17 \text { y }(\mathrm{N}=21)\end{array}$} & \multicolumn{2}{|c|}{$\begin{array}{l}\text { Children (proxy) } \\
\text { Age } 1-9 \text { y }(\mathrm{N}=19)\end{array}$} \\
\hline & $\begin{array}{l}\text { Pain } \\
(\mathrm{N}=82)^{*}\end{array}$ & $\begin{array}{l}\text { No Pain } \\
(\mathrm{N}=22)^{*}\end{array}$ & Pain $(\mathrm{N}=16)^{*}$ & $\begin{array}{l}\text { No Pain } \\
(\mathrm{N}=5)^{*}\end{array}$ & Pain $(\mathrm{N}=13)^{*}$ & $\begin{array}{l}\text { No Pain } \\
(\mathrm{N}=6)^{*}\end{array}$ \\
\hline \multicolumn{7}{|l|}{ Sociodemographic Variables } \\
\hline Age, y & $\begin{array}{c}43.17 \pm 13.00 \\
44(18-74)\end{array}$ & $\begin{array}{l}45.50 \pm 17.31 \\
43.50(18-72)\end{array}$ & $\begin{array}{c}13.75 \pm 2.30 \\
13.50(11-17)\end{array}$ & $\begin{array}{c}14.80 \pm 2.78 \\
16(10-17)\end{array}$ & $\begin{array}{l}6.38 \pm 2.26 \\
7(2-9)\end{array}$ & $\begin{array}{l}4.83 \pm 2.99 \\
5(1-9)\end{array}$ \\
\hline \multicolumn{7}{|l|}{ Education (completed level) } \\
\hline Primary school (1st-4th grade) & $5(6.1 \%)$ & $1(4.5 \%)$ & $11(68.8 \%)$ & $1(20 \%)$ & - & - \\
\hline Middle school (5th-9th grade) & $16(19.6 \%)$ & $9(40.9 \%)$ & $5(31.3 \%)$ & $4(80 \%)$ & - & - \\
\hline High school (10th-12th grade) & $33(40.2 \%)$ & $6(27.3 \%)$ & - & - & - & - \\
\hline College/postgraduate degree & $28(34.2 \%)$ & $6(27.2 \%)$ & - & - & - & - \\
\hline Marital status: married & $46(57.5 \%)[80]$ & $15(68.2 \%)$ & - & - & - & - \\
\hline Professional status & {$[81]$} & & & & & \\
\hline Student/kindergarten & $6(7.4 \%)$ & $3(13.6 \%)$ & $16(100 \%)$ & $5(100 \%)$ & $12(92.3 \%)$ & $6(100 \%)$ \\
\hline Full- or part-time job & $43(53.1 \%)$ & $14(63.6 \%)$ & - & - & - & - \\
\hline Unemployed & $8(9.9 \%)$ & 0 & - & - & - & - \\
\hline Retired & $22(27.2 \%)$ & $5(22.7 \%)$ & - & - & - & - \\
\hline Medical leave & $2(2.5 \%)$ & 0 & - & - & - & - \\
\hline If unemployed/retired/medical leave ${ }^{\dagger}$ & $\mathrm{N}=32$ & $\mathrm{~N}=5$ & - & - & - & - \\
\hline Due to hemophilia & $20(62.5 \%)$ & 0 & - & - & - & - \\
\hline Work/school/kindergarten & $\mathrm{N}=48^{\ddagger}$ & $\mathrm{N}=17^{\ddagger}$ & $\mathrm{N}=16$ & $\mathrm{~N}=5$ & $\mathrm{~N}=12$ & $\mathrm{~N}=6$ \\
\hline absences due to hemophilia & $26(54.2 \%)$ & $2(14.3 \%)[14]$ & $11(68.8 \%)$ & $1(20 \%)$ & $10(83.3 \%)$ & $4(66.7 \%)$ \\
\hline \multicolumn{7}{|l|}{ Clinical Variables } \\
\hline \multicolumn{7}{|l|}{ Type of hemophilia } \\
\hline Hemophilia A & $73(89 \%)$ & $15(68.2 \%)$ & $14(87.5 \%)$ & $5(100 \%)$ & $12(92.3 \%)$ & $6(100 \%)$ \\
\hline Hemophilia B & $9(11 \%)$ & $7(31.8 \%)$ & $2(12.5 \%)$ & 0 & $1(7.7 \%)$ & 0 \\
\hline \multicolumn{7}{|l|}{ Hemophilia severity } \\
\hline Mild & $7(8.5 \%)$ & $5(22.7 \%)$ & $3(18.8 \%)$ & $1(20 \%)$ & 0 & $1(16.7 \%)$ \\
\hline Moderate & $21(25.6 \%)$ & $12(54.5 \%)$ & $2(12.5 \%)$ & 0 & $4(30.8 \%)$ & $1(16.7 \%)$ \\
\hline Severe & $54(65.9 \%)$ & $5(22.7 \%)$ & $11(68.8 \%)$ & $4(80 \%)$ & $9(69.2 \%)$ & $4(66.7 \%)$ \\
\hline Prophylaxis treatment: Yes & $31(37.8 \%)$ & $3(13.6 \%)$ & $12(75 \%)$ & $4(80 \%)$ & $9(69.2 \%)$ & $4(66.7 \%)$ \\
\hline $\begin{array}{l}\text { Urgent hospital visits } \\
\text { due to hemophilia" }\end{array}$ & $45(59.2 \%)[76]$ & $6(31.6 \%)[19]$ & $11(84.6 \%)[13]$ & $2(40 \%)$ & $11(84.6 \%)$ & $2(40 \%)[5]$ \\
\hline $\begin{array}{l}\text { Hospitalization due to } \\
\text { hemophilia }{ }^{\text {II: }} \text { Yes }\end{array}$ & $10(12.2 \%)$ & $2(9.1 \%)$ & $2(12.5 \%)$ & $1(20 \%)$ & $4(30.8 \%)$ & 0 \\
\hline Bleeding episodes ${ }^{\mathrm{TI}}$ : Yes & $65(90.3 \%)[72]$ & $6(30 \%)[20]$ & $12(80 \%)[15]$ & $3(60 \%)$ & $10(76.9 \%)[11]$ & 0 \\
\hline Joint deterioration: Yes & $80(97.6 \%)$ & $9(42.9 \%)[21]$ & $9(56.3 \%)$ & $3(60 \%)$ & $6(46.2 \%)$ & $1(16.7 \%)$ \\
\hline
\end{tabular}

Continuous variables are presented as mean \pm SD and median (range). Categorical variables are presented as No. (\%).

"Unless otherwise specified in square brackets.

${ }^{\dagger}$ Assessed among participants reporting being unemployed, retired, or on medical leave.

${ }^{\ddagger}$ Assessed among participants who were working or studying.

II Data reporting to the previous year.

$68.2 \%$ ) and had a full- or part-time job (pain: 43, $53.1 \%$; no pain: $14,63.6 \%$ ). Among the adults in the pain group who were unemployed, retired, or on medical leave, $20(62.5 \%)$ reported being in that situation because of hemophilia. In the no pain group, no one attributed that status to hemophilia.
The mean age in the children/teenagers group (SD) was $13.75(2.30)$ years among participants with pain and $14.80(2.78)$ years in the no pain group. In younger children (age 1-9 years), the mean age was 6.38 (2.26) years in the pain group and $4.83(2.99)$ years in the no pain group. 
Table 3. Pain characteristics of people with hemophilia

\begin{tabular}{|c|c|c|c|}
\hline & $\begin{array}{l}\text { Adults Age } \geq 18 \mathrm{y} \\
(\mathrm{N}=82)^{\prime \prime}\end{array}$ & $\begin{array}{l}\text { Children/Teens Age 10-17y } \\
(\mathrm{N}=16)^{*}\end{array}$ & $\begin{array}{l}\text { Children (Proxy) Age 1-9y } \\
(\mathrm{N}=13)^{*}\end{array}$ \\
\hline No. of pain locations ${ }^{\dagger}$ & $\begin{array}{l}5.23 \pm 3.95 \\
4(1-16)\end{array}$ & $\begin{array}{l}4.13 \pm 3.48 \\
3.50(1-14)\end{array}$ & $\begin{array}{l}3.15 \pm 1.99 \\
2(1-6)\end{array}$ \\
\hline \multicolumn{4}{|l|}{ Pain location with more impact ${ }^{\dagger}$} \\
\hline Ankle & $31(37.8 \%)$ & $7(43.8 \%)$ & $6(46.2 \%)$ \\
\hline Knee & $30(36.6 \%)$ & $2(12.5 \%)$ & $3(23.1 \%)$ \\
\hline Elbow & $8(9.7 \%)$ & $3(18.8 \%)$ & $2(15.4 \%)$ \\
\hline Hip & $5(6.1 \%)$ & 0 & 0 \\
\hline Shoulder & $5(6.1 \%)$ & 0 & 0 \\
\hline Other & $3(3.7 \%)$ & $4(25 \%)$ & $2(15.4 \%)$ \\
\hline Pain duration, mo & $\begin{array}{c}137.70 \pm 136.46[63] \\
96(1-612)\end{array}$ & $\begin{array}{c}28.67 \pm 38.03[15] \\
6(1-108)\end{array}$ & $\begin{array}{c}16.00 \pm 20.79[7] \\
6(1-60)\end{array}$ \\
\hline \multicolumn{4}{|l|}{ Pain frequency ${ }^{\ddagger}$} \\
\hline a) After getting hurt or during bleeds & $20(24.4 \%)$ & $11(68.8 \%)$ & $9(69.2 \%)$ \\
\hline b) During physical efforts and/or movement & $34(41.5 \%)$ & $9(56.3 \%)$ & $5(38.5 \%)$ \\
\hline c) Weekly but not daily & $17(20.7 \%)$ & $1(6.3 \%)$ & 0 \\
\hline d) Daily but not constant & $15(18.3 \%)$ & 0 & 0 \\
\hline e) Always present, continuous, constant & $12(14.6 \%)$ & 0 & 0 \\
\hline Pain temporal pattern & [80] & & \\
\hline Morning & $15(18.8 \%)$ & $1(6.3 \%)$ & $1(7.7 \%)$ \\
\hline Afternoon & $5(6.3 \%)$ & 0 & $1(7.7 \%)$ \\
\hline End of the day & $11(13.8 \%)$ & $2(12.5 \%)$ & $2(15.4 \%)$ \\
\hline Night & $17(21.3 \%)$ & $1(6.3 \%)$ & $3(23.1 \%)$ \\
\hline Depends & $48(60 \%)$ & $12(75 \%)$ & $7(53.8 \%)$ \\
\hline \multicolumn{4}{|l|}{ Pain-triggering factors ${ }^{\ddagger}$} \\
\hline Bleeding episode & $43(52.4 \%)$ & $14(87.5 \%)$ & $9(69.2 \%)$ \\
\hline During physical efforts and/or movement & $61(74.4 \%)$ & $8(50 \%)$ & $6(46.2 \%)$ \\
\hline Using stairs & $33(40.2 \%)$ & $3(18.8 \%)$ & $2(15.4 \%)$ \\
\hline After resting or rising from sitting/lying down & $41(50 \%)$ & $2(12.5 \%)$ & 0 \\
\hline During rest, sitting, or lying down & $18(22 \%)$ & 0 & 0 \\
\hline Accidental or "wrong" movements & $45(54.9 \%)$ & $10(62.5 \%)$ & $1(7.7 \%)$ \\
\hline Weather changes & $34(41.5 \%)$ & $4(25 \%)$ & 0 \\
\hline Always present, constant & $10(12.2 \%)$ & $1(6.3 \%)$ & 0 \\
\hline
\end{tabular}

Continuous variables are presented as mean \pm SD and median (range). Categorical variables are presented as No. (\%).

"Unless otherwise specified in square brackets.

${ }^{\dagger}$ Data reporting to the previous year.

${ }^{\ddagger}$ More than one response option is possible.

Concerning clinical characteristics, most participants in all age groups had hemophilia A (Table 2). A higher number of participants with pain had severe hemophilia in all groups (age $\geq 18: 54,65.9 \%$; age 10-17: 11 , $68.8 \%$; age 1-9: 9, 69.2\%). Table 2 also highlights that urgent hospital visits, hospitalizations, bleeds, and joint deterioration were more often reported among participants with pain.

\section{Pain Characteristics of PWH}

\section{Pain Locations}

The mean number of pain locations reported (SD) was 5.23 (3.95) for adults, 4.13 (3.48) for children/teenagers, and 3.15 (1.99) for younger children. Pain in the lower limbs was considered by all age groups to cause the greatest negative impact, especially in the ankles (age $\geq 18: 31$, $37.8 \%$; age 10-17: 7, 43.8\%; age 1-9: 6, 25\%). This was followed by the knees in adults $(30,36.6 \%)$ and the $1-9$ age group $(3,23.1 \%)$, and by the elbows in the 10 17 age group $(8,9.7 \%)$ (Table 3$)$.

\section{Pain Duration}

The duration of the pain with the greatest impact ranged from 1 to 612 months ( 51 years) for adults and from 1 to 108 months (9 years) for children/teenagers. Parents reported pain in their children with hemophilia that ranged from 4 to 60 months (five years). The mean (SD) and median (range) values for pain duration are shown in Table 3.

\section{Pain Frequency and Temporal Pattern}

Concerning pain frequency, most adults indicated that pain was always present $(12,14.6 \%)$, occurring daily $(15,18.3 \%)$ or weekly $(17,20.7 \%)$. On the other hand, most children/teenagers and parents reported that pain was mostly associated with bleeding episodes (age 1017: $11,68.8 \%$; age 1-9: 9, 69.2\%) or physical efforts/ movements (age 10-17: 9, 56.3\%; age 1-9: 5, 38.5\%).

Table 3 also highlights that hemophilia-related pain does not present a specific temporal pattern, with most participants from all groups reporting that its onset is 

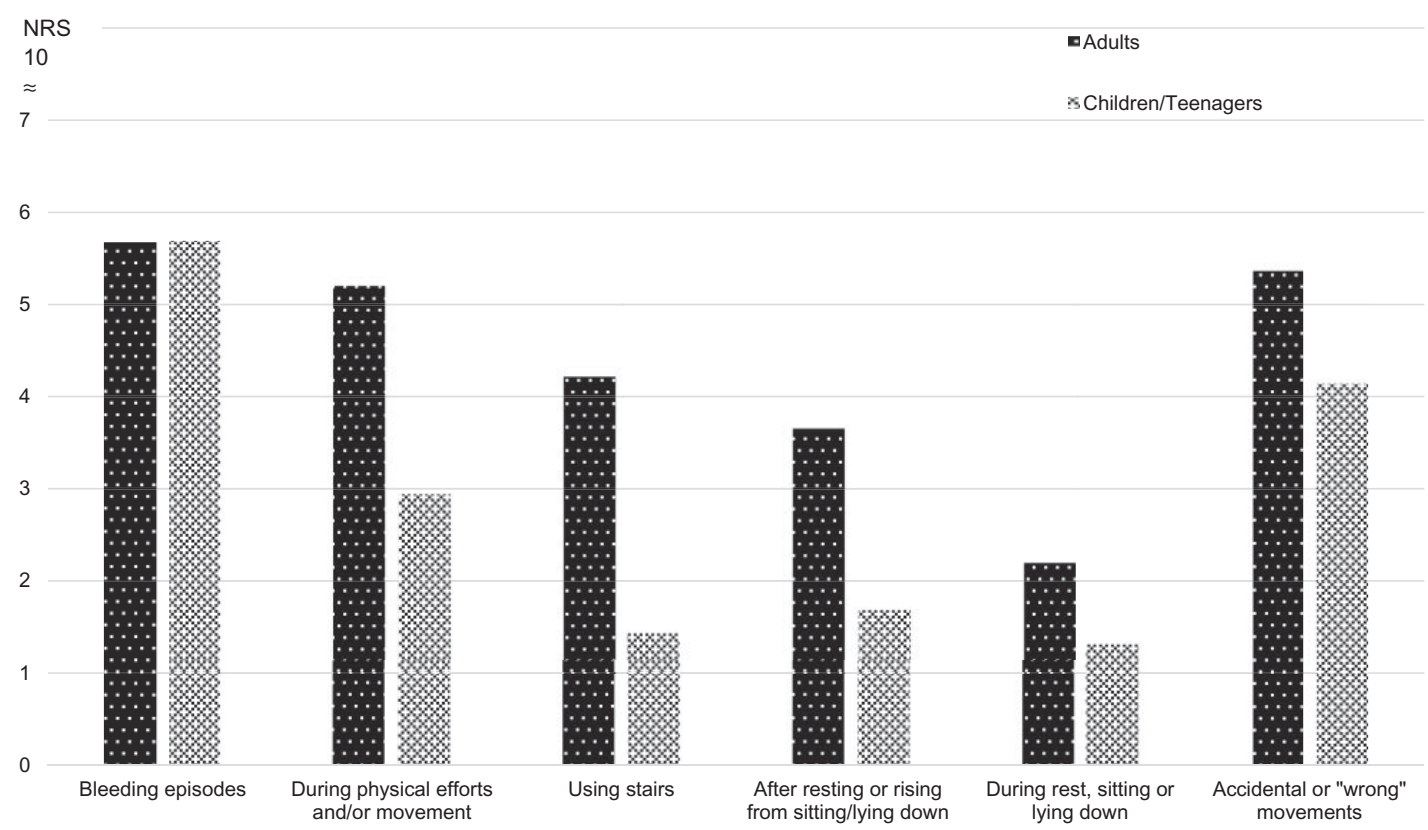

Figure 2. Pain intensity reported by adults (age $\geq 18$ years) and children/teenagers (age 10-17 years) with hemophilia.

variable (depends; age $\geq 18: 48,60 \%$; age $10-17: 12$, $75 \%$; age $1-9: 7,53.8 \%$ ).

\section{Pain-Triggering Factors}

The triggering factors for pain most frequently pointed out by adults were physical efforts and/or movements $(61,74.4 \%)$. About half the adults also highlighted pain after bleeding episodes $(43,52.4 \%)$, after resting or rising from sitting/lying down $(41,50 \%)$, and pain due to accidental/“wrong” movements (45, 54.9\%). Children and teenagers most frequently reported pain due to hemarthrosis (age 10-17: 14, 87.5\%; age 1-9: 9, $69.2 \%$ ). Table 3 shows a complete description of paintriggering factors selected by PWH.

\section{Pain Intensity}

As previously stated, pain intensity was only assessed on the self-report versions. The highest mean (SD) intensity score was reported for bleeding episodes, both by adults (5.67 [2.09]) and children/teenagers (5.69 [2.15]), followed by accidental or "wrong" movements (age $\geq 18$ : 5.35 [2.97]; age 10-17: 4.13 [3.32]). Pain during rest, sitting, or lying down had the lowest intensity score in the adults (2.20 [2.48]) and children/teenagers (1.31 [2.77]) groups (Figure 2).

\section{Pain Interference}

Adult PWH revealed the highest mean (SD) pain interference score on "walking ability" (5.65 [3.23]) and "normal work" (4.99 [2.70]), and the lowest on "relations with people" (2.93 [2.79]). In the children/ teenagers group, hemophilia-related pain had the highest mean interference score on "general activity" (4.44
[2.56]) and "normal work" (4.13 [2.78]), and the lowest on "enjoyment of life" (2.00 [2.85]) (Figure 3).

Parents of children up 1-9 years old revealed higher interference of their child's pain on "walking/crawling ability," with most reporting severe $(4,30.8 \%)$ or total (4, 30.8\%) interference. About one-third of parents $(30.8 \%)$ also pointed to severe or total interference in the "general activity" (severe: 1, 7.7\%; total: 3, 23.1\%) and "normal (school) work" (severe: 3, 23.1\%; total: 1, $7.7 \%$ ) domains. Around half the parents reported little interference of pain on "sleep" $(6,46.2 \%)$ and no interference on "relationship with others" $(6,46.2 \%)$. Only four parents $(30.8 \%)$ reported no interference of hemophilia on the child's mood, with most $(8,61.6 \%)$ reporting at least a moderate interference. The lowest interference was found for "enjoyment of life," with 10 $(76.9 \%)$ parents reporting little or no interference.

\section{Strategies for Pain Control}

The top five strategies used for pain management reported by PWH were the same for all groups: ice, rest, factor replacement, pain medication, and elevation. The strategy providing the greatest perception of relief $(0-100 \%$ scale) was factor replacement (age $\geq 18: 77.81$ [23.09]; age 10-17: 89.87 [16.40]), followed by pain medication (age $\geq 18: 59.33$ [23.67]; age 10-17: 65.36 [24.61]) (Figure 4).

\section{Pain Specialties or Other Therapies}

The health care professional most often consulted by the participants in this study was the hemophilia doctor (age $\geq 18: 71,86.6 \%$; age $10-17: 14,87.5 \%$; age $1-9$ : $13,100 \%)$. The specialist that most PWH "wished to consult" was the acupuncture specialist in the adults 

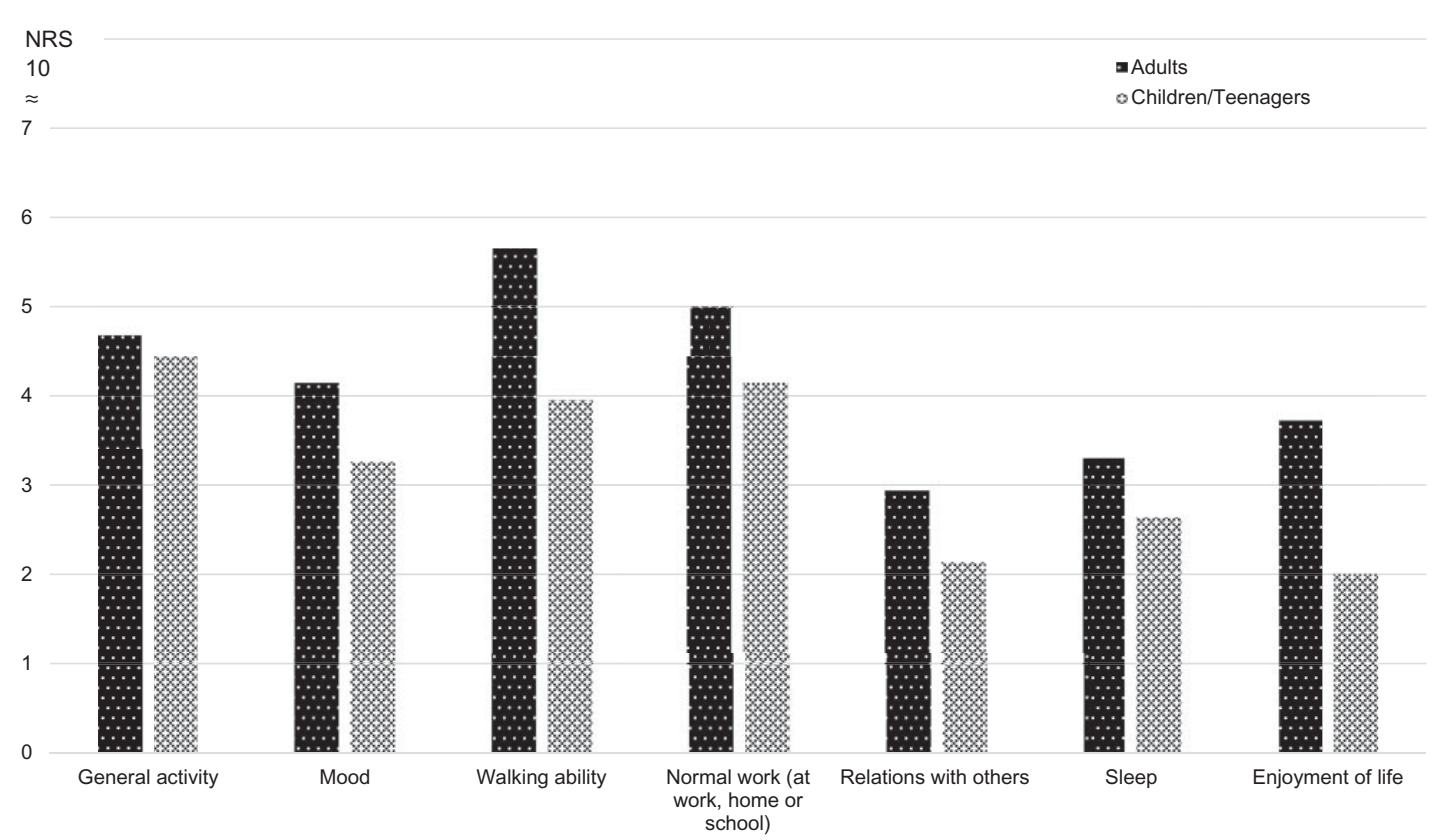

Figure 3. Pain interference reported by adults (age $\geq 18$ years) and children/teenagers (age 10-17 years) with hemophilia.

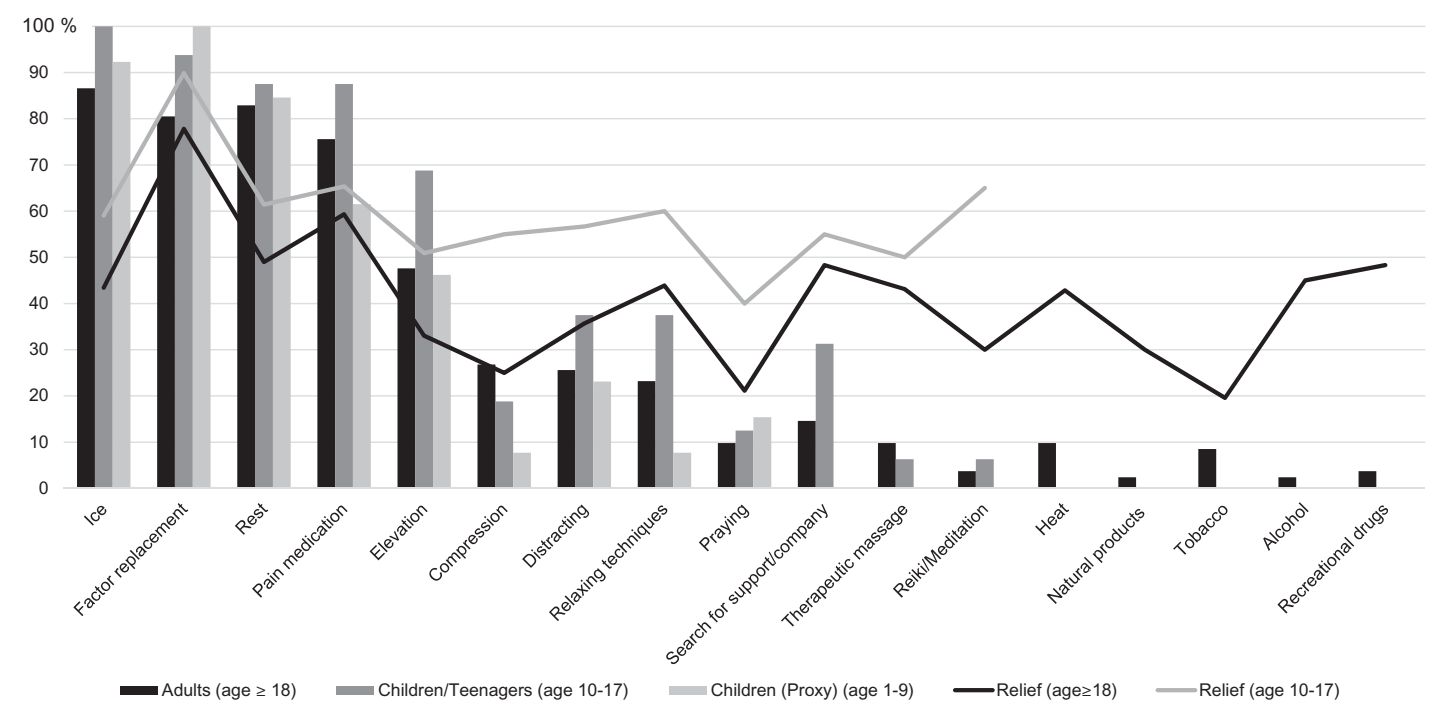

Figure 4. Strategies for pain control (adults, children/teenagers, and proxy version) and perception of relief provided (adults and children/teenagers).

group $(9,11 \%)$ and the reiki specialist in the children/ teenagers group $(3,18.8 \%)$. Parents of $1-9$-year-old children highlighted the psychologist $(2,15.4 \%)$ and the meditation specialist $(2,15.4 \%)$ (Figure 5 ).

Three adults stated that they had not consulted any specialist to assist in pain management (results not shown).

\section{Satisfaction with Pain Treatment}

Twelve $(15.4 \%)$ adults, but no participants in the children/teenagers group or parent version, reported being dissatisfied $(7,9 \%)$ or very dissatisfied $(5,6.4 \%)$ with pain treatment. Also, 28 (35.9\%) adults, three (18.8\%) children/teenagers, and one $(7.7 \%)$ parent stated that they were neither satisfied nor dissatisfied. The majority of children/teenagers and parents reported being satisfied (age 10-17: 5, 31.3\%; age 1-9: 7, 53.8\%) or very satisfied (age 10-17: 8, 50\%; age 1-9: 5, 38.5\%) with pain treatment. In the adults group, $31(39.7 \%)$ were satisfied and seven $(9 \%)$ very satisfied with pain treatment.

The Detrimental Impact of Pain on Well-being and Health-Related Quality of Life

In terms of what causes emotional distress among $\mathrm{PWH}$, Table 4 shows that, in participants with pain, there was a significantly higher prevalence of anxiety (odds ratio $[\mathrm{OR}]=1.698,95 \%$ confidence interval $[\mathrm{CI}]=1.190$ 2.422, $P=0.003)$ and depression $(\mathrm{OR}=1.961,95 \%$ 

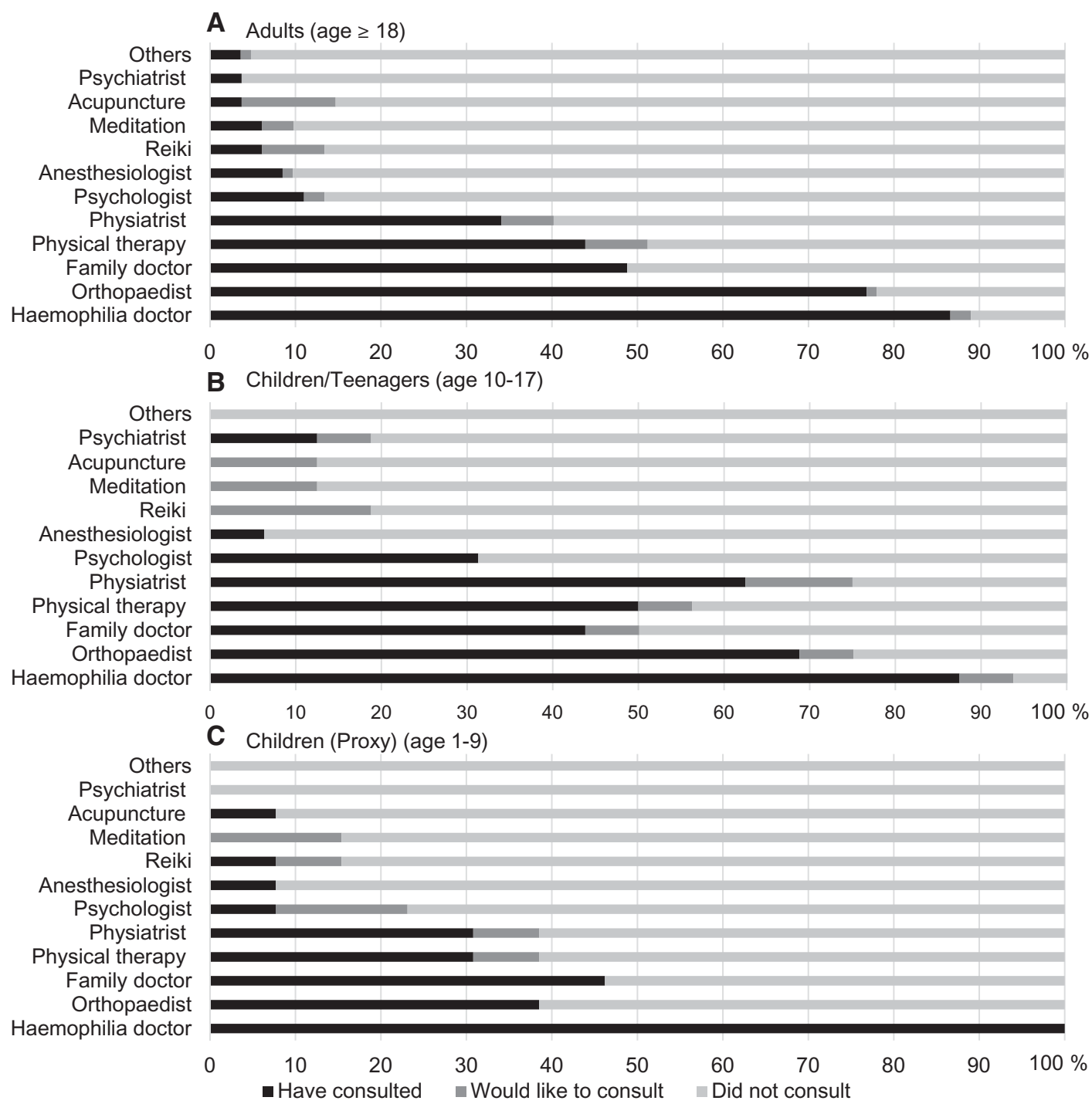

Figure 5. Pain specialties or other therapies that people with hemophilia have consulted or wished to consult.

$\mathrm{CI}=1.086-3.541, \quad P=0.025)$ symptoms, when compared with those participants with hemophilia who did not report hemophilia-related pain.

Regarding health-related quality of life, it was found that PWH with pain had significantly lower levels of global quality of life $(\mathrm{OR}=0.928,95 \% \mathrm{CI}=0.888$ $0.970, P=0.001)$ than PWH without pain. Furthermore, and with the exception of the dimension "treatment difficulties," Table 4 reveals that pain in hemophilia was associated with significantly lower scores of quality of life in all dimensions, such as physical health $(\mathrm{OR}=0.651,95 \% \mathrm{CI}=0.526-0.806, P<0.001)$, daily activities $\quad(\mathrm{OR}=0.591, \quad 95 \% \quad \mathrm{CI}=0.447-0.782$, $P<0.001$ ), joints $(\mathrm{OR}=0.484,95 \% \mathrm{CI}=0.330-0.712$, $P<0.001)$, treatment satisfaction $(\mathrm{OR}=0.639,95 \%$ $\mathrm{CI}=0.432-0.945, \quad P=0.025)$, emotional functioning $(\mathrm{OR}=0.762,95 \% \mathrm{CI}=0.645-0.899, P=0.001)$, mental health $(\mathrm{OR}=0.577,95 \% \mathrm{CI}=0.415-0.803, P=0.001)$, and relationships and social activity $(\mathrm{OR}=0.677,95 \%$ $\mathrm{CI}=0.517-0.886, P=0.005)$.

\section{Discussion}

This was the first nationwide hemophilia study conducted in Portugal aiming to understand the pain experience among people with hemophilia (PWH), describing its prevalence, characteristics, and impact. The detrimental impact of pain was emphasized across a variety of domains, also clearly showing the association of pain with more emotional distress and poor quality of life, which also increase the burden of the disease.

Findings from this survey provide, for the first time, relevant insights regarding pain among Portuguese patients living with hemophilia, drawing important conclusions concerning intervention needs and targets, and thereby contributing to the improvement of hemophiliarelated pain management and patient care.

\section{Pain Prevalence, Characteristics, and Impact}

The current findings confirm the high prevalence of pain among $\mathrm{PWH}$, with $77 \%$ of the participants reporting 
Table 4. Comparison of psychosocial factors between adult people with hemophilia with and without pain: Adjusted analyses

\begin{tabular}{|c|c|c|c|c|}
\hline Models (Final Models)" & Pain $(\mathrm{N}=82)$ & No Pain $(\mathrm{N}=22)$ & OR $(95 \% \mathrm{CI})$ & $P$ Value \\
\hline \multicolumn{5}{|c|}{ Emotional Distress-PROMIS } \\
\hline Anxiety & $7.56 \pm 3.07$ & $5.29 \pm 1.49$ & $1.698(1.190-2.422)$ & 0.003 \\
\hline Depression & $6.77 \pm 3.47$ & $4.29 \pm 0.78$ & $1.961(1.086-3.541)$ & 0.025 \\
\hline \multicolumn{5}{|l|}{ HQoL-A36 Hemofilia-QoL } \\
\hline Global HQoL & $49.40 \pm 25.52$ & $83.87 \pm 16.90$ & $0.928(0.888-0.970)$ & 0.001 \\
\hline Physical health & $54.20 \pm 25.83$ & $88.76 \pm 14.53$ & $0.651(0.526-0.806)$ & $<0.001$ \\
\hline Daily activities & $50.23 \pm 29.50$ & $91.48 \pm 13.63$ & $0.591(0.447-0.782)$ & $<0.001$ \\
\hline Joints & $51.72 \pm 27.94$ & $89.25 \pm 13.94$ & $0.484(0.330-0.712)$ & $<0.001$ \\
\hline Treatment satisfaction & $58.50 \pm 28.81$ & $72.61 \pm 28.78$ & $0.639(0.432-0.945)$ & 0.025 \\
\hline Treatment difficulties & $54.16 \pm 32.04$ & $67.72 \pm 25.44$ & $0.920(0.764-1.108)$ & 0.379 \\
\hline Emotional functioning & $47.62 \pm 31.52$ & $79.29 \pm 18.02$ & $0.762(0.645-0.899)$ & 0.001 \\
\hline Mental health & $57.64 \pm 27.40$ & $81.90 \pm 17.89$ & $0.577(0.415-0.803)$ & 0.001 \\
\hline Rel. \& social activity & $52.81 \pm 30.64$ & $85.16 \pm 21.64$ & $0.677(0.517-0.886)$ & 0.005 \\
\hline
\end{tabular}

Anxiety: $\chi^{2}(3)=23.929, P<0.001$, Nagelkerke $R^{2}=0.328$; final model correctly predicted $82.4 \%$ of all participants. Depression: $\chi^{2}(3)=22.470, P<0.001$, Nagelkerke $R^{2}=0.310$; final model correctly predicted $80.4 \%$ of all participants. Global HQoL: $\chi^{2}(3)=54.955, P<0.001$, Nagelkerke $R^{2}=0.416$; final model correctly predicted $87.4 \%$ of all participants. Physical health: $\chi^{2}(3)=41.810, P<0.001$, Nagelkerke $R^{2}=0.532$; final model correctly predicted $89.0 \%$ of all participants. Daily activities: $\chi^{2}(3)=40.973, P<0.001$, Nagelkerke $R^{2}=0.516$; final model correctly predicted $89.3 \%$ of all participants. Joints: $\chi^{2}(3)=35.303$, $P<0.001$, Nagelkerke $R^{2}=0.466$; final model correctly predicted $83.3 \%$ of all participants. Treatment satisfaction: $\chi^{2}(3)=16.223, P=0.001$, Nagelkerke $R^{2}=0.248$; final model correctly predicted $83.7 \%$ of all participants. Treatment difficulties: $\chi^{2}(3)=8.268, P=0.041$, Nagelkerke $R^{2}=0.132$. Emotional functioning: $\chi^{2}(3)=25.030, P<0.001$, Nagelkerke $R^{2}=0.345$; final model correctly predicted $80.0 \%$ of all participants. Mental health: $\chi^{2}(3)=26.629, P<0.001$, Nagelkerke $R^{2}=0.360$; final model correctly predicted $81.4 \%$ of all participants. Rel. \& social activity: $\chi^{2}(3)=25.689, P=0.001$, Nagelkerke $R^{2}=0.368$; final model correctly predicted $86.7 \%$ of all participants.

Sample size is not constant due to missing data in the pain group: anxiety $(\mathrm{N}=81)$, depression $(\mathrm{N}=81)$, HQoL total $(\mathrm{N}=72)$, physical health $(\mathrm{N}=79)$, daily activities $(\mathrm{N}=82)$, joints $(\mathrm{N}=82)$, treatment satisfaction $(\mathrm{N}=80)$, treatment difficulties $(\mathrm{N}=80)$, emotional functioning $(\mathrm{N}=79)$, mental health $(\mathrm{N}=81)$, relationships \& social activity $(\mathrm{N}=79)$; and in the no pain group: anxiety $(\mathrm{N}=21)$, depression $(\mathrm{N}=21)$, HQoL total $(\mathrm{N}=15)$, physical health $(\mathrm{N}=21)$, daily activities $(\mathrm{N}=21)$, joints $(\mathrm{N}=20)$, treatment satisfaction $(\mathrm{N}=18)$, treatment difficulties $(\mathrm{N}=18)$, emotional functioning $(\mathrm{N}=21)$, mental health $(\mathrm{N}=21)$, relationships \& social activity $(\mathrm{N}=19)$.

Continuous variables are presented as mean $\pm \mathrm{SD}$.

$\mathrm{CI}=$ confidence interval; $\mathrm{HQoL}=$ health-related quality of life; PROMIS = Patient-Reported Outcomes Measurement Information System.

"To adjust for the differences between groups, two potential confounders were included in each model as covariates: age and hemophilia severity (mild, moderate, severe).

pain due to hemophilia in the previous year. It is hard to establish comparisons of pain reports across studies given the variety of methods, time frames, and definitions used. For instance, a Dutch survey [11] reported a pain prevalence of $81 \%$, albeit only including severe hemophilia, and an American survey [15] found a prevalence of $85 \%$, though only considering the last six months. Regarding children and adolescents, a German survey showed a prevalence of $66 \%$, though pain was not necessarily related to hemophilia, with another study [14] revealing lower figures $(20.8 \%)$ despite only considering pain occurrence on the assessment day. Specifically, chronic hemophilia-related pain was reported by $8 \%$ of children and $35 \%$ of adults in a survey performed across 22 European hemophilia centers [27], and in another survey conducted among 10 countries, general prevalence was $38 \%$ [28]. Nevertheless, these studies relied on health professionals' and patients' responses to a single direct question asking about chronic pain. Indeed, PWH experience acute pain during joint bleeds (hemarthrosis), but also chronic pain resulting from hemophilic arthropathy [3]. Witkop et al. [15] considered this distinction, specifying a prevalence of $66 \%$ for chronic pain and $20 \%$ for acute pain and, interestingly, reported $32 \%$ experiencing concurrent acute and chronic pain. However, it is not clear how exactly they distinguished between acute and chronic pain.

With this scope in mind, and in order to accurately classify hemophilia-related pain as chronic, a definition was proposed [27], requiring that pain should be continuous and/or intermittent, lasting over three months and occurring more than once a week.

A clear distinction between acute and chronic pain is of paramount importance, as chronic pain is much more complex, being associated with neurobiological and psychosocial factors that might perpetuate it, with evident implications for treatment strategies. Hence, in the current survey, these guidelines were taken into account, as the pain questionnaire under use carefully considered this distinction. Consequently, it was possible to uncover that among the $77 \%$ of $\mathrm{PWH}$ reporting pain, $59.7 \%$ of them had pain lasting more than three months and $31.9 \%$ experienced pain more than once a week. This gives a more accurate insight on pain chronicity, circumventing the limitation of the aforementioned surveys. Together with the information collected through additional questions, it is indisputable that pain is a very significant condition for the majority of Portuguese PWH. Illustrating this is the fact that many adults revealed a high duration and frequency of pain, lasting, in some cases, more than 
50 years and occuring on a daily or weekly basis, or even constantly.

The simultaneous occurrence of pain in multiple locations in the same individual, previously reported [11,29], also emphasizes the challenge posed by hemophilia-related pain in terms of management and control. It is particularly demanding to control and cope with pain that can occur simultaneously in five, four, and three locations, as indicated by adults, adolescents, and children, respectively. Furthermore, the ankles and the knees have shown up as the pain locations yielding the highest negative impact among all age groups, corroborating findings from other countries [11,29-31]. Pain in lower limbs entails several limitations to peoples' mobility and general daily activities. It is noteworthy that the greatest pain interference scores were in general activity, walking ability, normal work, and mood, congruent with other findings [30]; these results point to the particular challenges posed by ankle and knee pain, more than pain from upper extremities.

Findings concerning pain characteristics and interference can help explain data on adults' satisfaction with pain treatment, with $15.4 \%$ saying they were not satisfied with pain treatment. Comparatively, satisfaction rates are higher among younger patients, which may be due to shorter pain duration and less severe joint complications, attributable to early prophylaxis treatment [2].

Concerning quality of life, this survey also reveals that all its dimensions were substantially more affected in pain participants, matching previous findings $[12,15,31]$, and that the detrimental impact of pain goes beyond the physical domain. Indeed, the current findings clearly demonstrate that anxiety and depression symptoms were much more pronounced among pain patients. Concomitantly, the low scores in the "mental health," "emotional functioning," and "relationships and social activity" domains of the health-related quality of life scale reinforced this conclusion. This is in agreement with other studies, which showed that pain affected the $\operatorname{mood}$ of $85 \%$ of PWH [29] and that those reporting pain are more likely to be depressed [15], underscoring the need to consider mental health issues when evaluating pain among PWH [33].

Regarding pain intensity, the highest mean intensity was for acute pain (hemarthrosis), both for adults (5.67; 0-10 NRS) and children/teenagers (5.69; 0-10 NRS), which is in agreement with findings $(5.95 ; 0-10$ NRS) from the United States [32]. Other studies [15,29] reported pain intensity levels but considered, for instance, worst and average pain, disregarding the acute and chronic pain distinction and thus hampering the likelihood of conceiving and providing effective pain relief strategies tailored to the nature of pain and its triggers. Intensity concerning chronic pain was also gathered in this survey, considering distinct situations, such as pain during movement or rest. This was an important strength of the present survey, as to our knowledge no such accurate and detailed assessment has been conducted among PWH. Reductions in pain intensity translate into improved quality of life. Thus, through such an accurate assessment of pain intensity, according to the specific pain trigger situation, a special focus can then be placed on patients who suffer from high pain intensities that affect their everyday lives.

\section{The Need to Expand Pain Care and Promote Nonpharmacological Strategies}

When asked about pain control strategies, most patients stated that they use some elements of the RICE strategy (rest, ice, compression, and elevation), in line with current guidelines for pain management $[1,27]$. Factor replacement therapy also emerges as one of the most used strategies, and the one providing the greatest perception of relief. In this matter, it should be noted that factor replacement is not recommended to reduce pain, but to stop the bleeding episode, which triggers acute pain. In Portugal, factor replacement is available for all hemophilia patients after hemarthrosis (on demand) to stop bleeding, with a recent survey also describing increasingly greater access to home treatment for Portuguese patients [5].

Concerning specialties or therapies for pain management, an interesting percentage of $\mathrm{PWH}$ mentioned nonpharmacological techniques and the wish to consult pain professionals conducting nonpharmacological interventions. Interestingly, this matches the recommendations of international hemophilia guidelines, which state that nonpharmacological treatments, such as psychological interventions, should be considered for pain control [27]. In Portugal, all persons have access to the public National Health System, though access to some specialties, such as psychology, might be hindered by the low number of professionals working in public hospitals. In addition, access to complementary pain therapies (e.g., acupuncture) is limited in public hospitals. Thus, the use of complementary pain therapies is still incipient among Portuguese $\mathrm{PWH}$, despite guidelines and recommendations stating that a combined approach of pharmacological and nonpharmacological strategies (such as psychosocial interventions) is optimal for pain management in hemophilia $[27,34]$. This fact is indeed corroborated by a survey of hemophilia care in Europe, which reports a decrease in access to social and psychological support by PWH in Portugal [5].

Psychological interventions have been proven to be cost-effective in a broad range of disorders and illnesses [35-39]. Although a few former works have focused on psychological interventions in hemophilia, showing positive and promising results [40-44], it is surprising that there has been a lack of recent works exploring this issue, despite the recommendations and guidelines that emphasize their relevance. In those publications, a blend of 
psychological techniques was applied, with particular emphasis on hypnosis $[37,38,42,43]$. In fact, there is considerable evidence for the effectiveness of hypnosis as an empirically supported clinical intervention in managing symptoms such as pain [22,45-48] and in promoting psychological well-being $[49,50]$. Among PWH, studies have shown that hypnosis can contribute not only to controlling pain, but also to reducing the frequency and severity of bleeds and factor consumption [37,38,41]. Concurrently, by promoting better disease management, hypnosis can contribute to better coping and less distress [41].

In sum, and despite the shortage of recent studies focused on psychological interventions in hemophilia, these are recognized as complementary nonpharmacologic therapies and should be more often considered as a valuable resource to expand hemophilia care and potentially maximize treatment outcomes, promoting quality of life and emotional well-being and improving symptom management $[34,51]$.

\section{Limitations}

This is a cross-sectional study, preventing the establishment of cause-effect associations. The representativeness of the participants could not be controlled, and the low response rate may be responsible for some nonresponse bias. Moreover, there was a small sample size in the 10-17 and 1-9 age groups, stemming from the rarity of this disease, and limiting the use of more accurate statistical procedures. Future research with larger sample sizes and longitudinal assessment of outcomes is thus warranted. This would allow for more robust conclusions concerning which variables might be associated with increased pain and the potential mediating or moderating effect of psychological characteristics between disease variables and outcomes. Another limitation concerns the lack of information regarding pharmacological treatment. Even though this survey included an open question regarding medication intake, we concluded that some of the answers provided were not very clear in terms of the nomenclature used, leaving some doubts about the data, which justified their exclusion from the analysis. A careful assessment of pharmacological treatments and potential substance use disorders among this population should be included in future pain surveys. Finally, it would be of interest to compare PWH with pain and without pain in terms of objectively measured outcomes, such as a clinical/radiological assessment of joint status.

\section{Conclusions}

This study has confirmed unequivocally that pain is highly prevalent among Portuguese PWH of all ages, as in other countries. Furthermore, it was clearly demonstrated that pain in hemophilia yields a significant negative impact on peoples' lives and is associated with more emotional distress and poor quality of life, which undoubtedly increases the burden of this disease.

The improvement of evidence-based pain management guidelines and effective practices is therefore imperative and must be a priority in hemophilia care. Three issues are crucial and should be considered: a closer collaboration between hemophilia clinicians and pain specialists; the implementation of effective pain control strategies that include both pharmacological and nonpharmacological approaches, namely psychological strategies; and, finally, the recognition of pain as a critical hemophilia issue by hemophilia health care providers and policy makers.

Definitively, these findings give important clues toward the improvement of health care services and comprehensive hemophilia pain care, also informing the conception and design of more tailored pain management plans.

\section{Acknowledgments}

The authors thank the Portuguese Haemophilia Association for help in contacting the participants for this study. We also acknowledge the clinicians from the Centre of Haemophilia (Department of Transfusion Medicine and Blood Bank) of Centro Hospitalar São João, Porto, Portugal, for their medical expertise and assistance.

\section{References}

1. Srivastava A, Brewer AK, Mauser-Bunschoten EP, et al. Guidelines for the management of hemophilia. Haemophilia 2013;19(1):e1-e47.

2. Ljung R, Andersson N. The current status of prophylactic replacement therapy in children and adults with haemophilia. Br J Haematol 2015;169 (6):777-86.

3. Lobet S, Hermans C, Lambert C. Optimal management of hemophilic arthropathy and hematomas. J Blood Med 2014;5:207-18.

4. White GC, Rosendaal F, Aledort LM, et al. Definitions in hemophilia. Recommendation of the Scientific Subcommittee on Factor VIII and Factor IX of the Scientific and Standardization Committee of the International Society on Thrombosis and Haemostasis. Thromb Haemost 2001;85(3):560.

5. Mahony BO, Savini L, Hara JO, Bok A. Haemophilia care in Europe - a survey of 37 countries. Haemophilia 2017;23(4):e259-e66.

6. Flood E, Pocoski J, Michaels LA, et al. Illustrating the impact of mild/moderate and severe haemophilia on health-related quality of life: Hypothesised conceptual models. Eur J Haematol 2014;93:9-18. 
7. Gringeri A, Ewenstein B, Reininger A. The burden of bleeding in haemophilia: Is one bleed too many? Haemophilia 2014;20(4):459-63.

8. Pulles AE, Mastbergen SC, Schutgens REG, Lafeber FPJG, van Vulpen LFD. Pathophysiology of hemophilic arthropathy and potential targets for therapy. Pharmacol Res 2017;115:192-9.

9. Roosendaal G, Lafeber FP. Pathogenesis of haemophilic arthropathy. Haemophilia 2006;12 (s3):117-21.

10. Valentino LA. Blood-induced joint disease: The pathophysiology of hemophilic arthropathy. J Thromb Haemost 2010;8(9):1895-902.

11. Genderen FR, Fischer K, Heijnen L, et al. Pain and functional limitations in patients with severe haemophilia. Haemophilia 2006;12(2):147-53.

12. Forsyth AL, Witkop M, Lambing A, et al. Associations of quality of life, pain, and self-reported arthritis with age, employment, bleed rate, and utilization of hemophilia treatment center and health care provider services: Results in adults with hemophilia in the HERO study. Patient Prefer Adherence 2015;9 :1549-60.

13. Kalnins W, Schelle G, Jost K, Eberl W, Tiede A. Pain therapy in haemophilia in Germany. Patient survey (BESTH Study). Hamostaseologie 2015;35 (2):167-73

14. Rambod M, Forsyth K, Sharif F, Khair K. Assessment and management of pain in children and adolescents with bleeding disorders: A cross-sectional study from three haemophilia centres. Haemophilia 2016;22 (1):65-71.

15. Witkop M, Neff A, Buckner TW, et al. Self-reported prevalence, description and management of pain in adults with haemophilia: Methods, demographics and results from the Pain, Functional Impairment, and Quality of life (P-FiQ) study. Haemophilia 2017; 23(4):556-65.

16. McLaughlin JM, Munn JE, Anderson TL, et al. Predictors of quality of life among adolescents and young adults with a bleeding disorder. Health Qual Life Outcomes 2017;15(1):15-67.

17. van Genderen FR, van Meeteren NL, Heijnen L, van den Berg HM, Helders PJ. The use of a disability model in haemophilia research. Haemophilia 2005; 11(5):472-80.

18. World Federation of Haemophilia. Report on the Annual Global Survey 2016. Montreal, Canada:World Federation of Haemophilia; 2017.

19. Humphries TJ, Kessler CM. Pain in haemophilia: Are we listening? Haemophilia 2016;22(2):175-8.

20. Riley RR, Witkop M, Hellman E, Akins S. Assessment and management of pain in haemophilia patients. Haemophilia 2011;17(6):839-45.

21. Pocoski J, Benjamin K, Michaels LA, Flood E, Sasane R. An overview of current trends and gaps in patient- reported outcome measures used in haemophilia. Eur J Haematol 2014;93(Suppl 75):1-8.

22. Cleeland CS, Ryan KM. Pain assessment: global use of the Brief Pain Inventory. Ann Acad Med Singapore 1994;23(2):129-38.

23. Paredes AC, Costa P, Almeida A, Pinto PR. A new measure to assess pain in people with haemophilia: The Multidimensional Haemophilia Pain Questionnaire (MHPQ). PloS one 2018;13(11):e0207939.

24. Pilkonis PA, Choi SW, Reise SP, et al. Item banks for measuring emotional distress from the PatientReported Outcomes Measurement Information System (PROMIS(R)): Depression, anxiety, and anger. Assessment 2011;18(3):263-83.

25. Remor E, Arranz P, Quintana M, et al. Psychometric field study of the new Haemophilia Quality of Life Questionnaire for adults: The 'Hemofilia-QoL'. Haemophilia 2005;11(6):603-10.

26. Cronbach LJ. Coefficient alpha and the internal structure of tests. Psychometrika 1951;16(3):297-334.

27. Holstein K, Klamroth R, Richards M, et al. Pain management in patients with haemophilia: A European survey. Haemophilia 2012;18(5):743-52.

28. Forsyth AL, Gregory M, Nugent D, et al. Haemophilia Experiences, Results and Opportunities (HERO) study: Survey methodology and population demographics. Haemophilia 2014;20(1):44-51.

29. Wallny T, Hess L, Seuser A, et al. Pain status of patients with severe haemophilic arthropathy. Haemophilia 2001;7(5):453-8.

30. Kempton CL, Recht M, Neff A, et al. Impact of pain and functional impairment in US adults with haemophilia: Patient-reported outcomes and musculoskeletal evaluation in the pain, functional impairment and quality of life (P-FiQ) study. Haemophilia 2018;24 (2):261-70.

31. Genderen FR, Westers P, Heijnen L, et al. Measuring patients' perceptions on their functional abilities: Validation of the Haemophilia Activities List. Haemophilia 2006;12(1):36-46.

32. Witkop M, Lambing A, Divine G, et al. A national study of pain in the bleeding disorders community: A description of haemophilia pain. Haemophilia 2012; 18(3):e115-9.

33. Kempton CL, Buckner TW, Fridman M, Iyer NN, Cooper DL. Factors associated with pain severity, pain interference, and perception of functional abilities independent of joint status in US adults with hemophilia: Multivariable analysis of the Pain, Functional Impairment, and Quality of Life (PFiQ) study. Eur J Haematol 2018;100(Suppl 1):25-33.

34. Young G, Tachdjian R, Baumann K, Panopoulos G. Comprehensive management of chronic pain in haemophilia. Haemophilia 2014;20(2):e113-20. 
35. Carlson LE, Bultz BD. Efficacy and medical cost offset of psychosocial interventions in cancer care: Making the case for economic analyses. Psychooncology 2004;13(12):837-49; discussion 50-6.

36. Frederiksen Y, Farver-Vestergaard I, Skovgård NG, Ingerslev HJ, Zachariae R. Efficacy of psychosocial interventions for psychological and pregnancy outcomes in infertile women and men: A systematic review and meta-analysis. BMJ Open 2015;5:e006592.

37. LaBaw W. Auto-hypnosis in haemophilia. Haematologica 1975;9(1-2):103-10.

38. Lucas ON. The use oh hypnosis in haemophilia dental care. Ann N Y Acad Sci 1975;20:263-6.

39. Williams AC, Eccleston C, Morley S. Psychological therapies for the management of chronic pain (excluding headache) in adults. Cochrane Database Syst Rev 2012;11:CD007407.

40. LaBaw W. The use of hypnosis with hemophilia. Psychiatr Med 1992;10(4):89-98.

41. Swirsky-Sacchetti T, Margolis CG. The effects of a comprehensive self-hypnosis training program on the use of factor VIII in severe hemophilia. Int J Clin Exp Hypn 1986;34(2):71-83.

42. Varni JW. Behavioral medicine in hemophilia arthritic pain management: Two case studies. Arch Phys Med Rehabil 1981;62(4):183-7.

43. Varni JW. Self-regulation techniques in the management of chronic arthritic pain in hemophilia. Behav Ther 1981;12(2):185-94.
44. Varni JW, Gilbert A. Self-regulation of chronic arthritic pain and long-term analgesic dependence in a haemophiliac. Rheumatol Rehabil 1982;21 (3):171-4.

45. Montgomery GH, David D, Winkel G, Silverstein JH, Bovbjerg DH. The effectiveness of adjunctive hypnosis with surgical patients: A meta-analysis. Anesth Analg 2002;94(6):1639-45.

46. Jensen M, Patterson DR. Hypnotic treatment of chronic pain. J Behav Med 2006;29(1):95-124.

47. Lang EV, Rosen MP. Cost analysis of adjunct hypnosis with sedation during outpatient interventional radiologic procedures. Radiology 2002;222(2):375-82.

48. Tefikow S, Barth J, Maichrowitz S, et al. Efficacy of hypnosis in adults undergoing surgery or medical procedures: A meta-analysis of randomized controlled trials. Clin Psychol Rev 2013;33(5):623-36.

49. Montgomery GH, Bovbjerg DH, Schnur JB, et al. A randomized clinical trial of a brief hypnosis intervention to control side effects in breast surgery patients. J Nat Cancer Inst 2007;99(17):1304-12.

50. Palsson OS, Turner MJ, Johnson DA, Burnett CK, Whitehead WE. Hypnosis treatment for severe irritable bowel syndrome: Investigation of mechanism and effects on symptoms. Dig Dis Sci 2002;47(11):2605-14.

51. Cassis F, Emiliani F, Pasi J, Palareti L, Iorio A. Psychological interventions for people with hemophilia. Cochrane Database Syst Rev 2012;11: CD010215. 